\title{
Monoclonal gammopathy of undetermined significance (MGUS): where is the hidden danger? Definition and work-up
}

\author{
Georg Jeryczynski · Maria-Theresa Krauth
}

Received: 26 April 2020 / Accepted: 23 June 2020 / Published online: 13 July 2020

(C) The Author(s) 2020

\begin{abstract}
Summary Monoclonal gammopathy of undetermined significance (MGUS) is a premalignant hematological condition arising from B-cells, characterized by the presence of monoclonal immunoglobulin production, also known as paraprotein. It is found in up to $3 \%$ of individuals over the age of 50 years. The overall progression rate is low at around $1 \%$ per year, with most patients progressing to multiple myeloma (MM). Other diseases that may arise from MGUS include non-Hodgkin lymphomas, Waldenström macroglobulinemia, amyloid light-chain (AL) amyloidosis, POEMS (polyneuropathy, organomegaly, endocrinopathy, M-protein, skin changes), cryoglobulinemia, monoclonal gammopathy of renal significance (MGRS), and additional paraprotein-driven diseases. Every case of monoclonal gammopathy warrants careful investigation to rule out the presence of a malignant form. In recent years, paraprotein-associated conditions such as MGRS have been increasingly recognized. Accurate diagnosis and work-up of these cases require a multidisciplinary approach, and it is paramount to accurately distinguish them from true MGUS in order to prevent end-organ damage. Follow-up of MGUS should be lifelong; however, a riskadapted approach involving the primary care setting is recommended.
\end{abstract}

\footnotetext{
G. Jeryczynski

Division of Oncology, Department of Medicine

I, Medical University of Vienna, Waehringer

Guertel 18-20, 1090 Vienna, Austria

georg.jeryczynski@meduniwien.ac.at
}

\section{M.-T. Krauth ( $ه)$}

Division of Hematology and Hemostaseology, Department of Medicine I, Medical University of Vienna, Waehringer Guertel 18-20, 1090 Vienna, Austria

maria.krauth@meduniwien.ac.at
Keywords MGUS · Paraproteinemia - MGRS · MGCS · Multiple myeloma

\section{Definition and epidemiology}

Monoclonal gammopathy of undetermined significance (MGUS) is a premalignant B-cell neoplasia usually arising from plasma cells and less frequently from lymphoplasmacytic cells. It is defined as a serum monoclonal protein of less than $30 \mathrm{~g} / \mathrm{L}$, less than $10 \%$ of clonal plasma or lymphoplasmacytic cells in the bone marrow, and the absence of end-organ damage, myeloma defining events, or any constitutional symptoms [1]. Its prevalence increases with age. While it is a rare occurrence in patients younger than 50 years, it is found in $1.7 \%$ of individuals aged between 50 and 59 years, with slightly more men being affected. This proportion increases to up to $7.5 \%$ in persons older than 85 years. The most common immunoglobulin isotypes are immunoglobulin G (IgG) and Kappa light chain [2].

\section{Progression and risk stratification}

MGUS has an overall low risk of progression to multiple myeloma (MM) or other associated diseases. Depending on the immunoglobulin subtype, the rate of progression can vary from $0.3 \%$ per year in lightchain MGUS to $1.5 \%$ in IgM MGUS. While the rate of progression remains stable in non-IgM MGUS, it decreases in IgM MGUS from $2 \%$ in the first decade to $1 \%$ after 10 years. The vast majority of IgM MGUS progress to Waldenström macroglobulinemia (WM), while IgM MM is exceedingly rare [3]. In more than $90 \%$ of WM patients the MYD88 L265P mutation can be detected [4], while it is not found in MM. In a very rare subset of patients with lymphoplasmacytic lymphoma, IgG, or IgA paraprotein may be found; 
Table 1 Mayo Clinic risk model [7]

\begin{tabular}{|c|c|c|}
\hline Risk factors & $\begin{array}{l}\text { Percentage } \\
\text { of patients }\end{array}$ & $\begin{array}{l}\text { Risk of progression } \\
\text { at } 20 \text { years } \\
(\%)\end{array}$ \\
\hline $\begin{array}{l}\text { Low risk (serum M-protein }<15 \mathrm{~g} / \mathrm{L} \text {, } \\
\text { IgG subtype and FLC ratio } 0.26-1.65 \text { ) }\end{array}$ & 39 & 5 \\
\hline $\begin{array}{l}\text { Low-intermediate risk (any one factor } \\
\text { abnormal) }\end{array}$ & 37 & 21 \\
\hline $\begin{array}{l}\text { High-intermediate risk (any two } \\
\text { factors abnormal) }\end{array}$ & 20 & 37 \\
\hline High risk (all three factors abnormal) & 5 & 58 \\
\hline
\end{tabular}

however, the MYD88 mutation frequency appears to be lower in these cases [5].

Several risk factors for progression have been identified. An M-spike of $\geq 15 \mathrm{~g} / \mathrm{L}$ is the most important determinant for progression. Further important risk factors include an IgA isotype, an abnormal light chain ratio, a rise in the $\mathrm{M}$-protein level over time, a bone marrow plasma cell percentage of more than $5 \%$, a reduction of both uninvolved isotypes, and circulating plasma cells in the blood [6].

Based on the known risk factors, Rajkumar et al. developed a model that incorporates the following biomarkers: non-IgG MGUS, M-protein of $\geq 15 \mathrm{~g} / \mathrm{L}$, and abnormal free light chain (FLC) ratio of $<0.125$ or $>8$. Depending on the presence of none, one, two, or all three risk factors, the rate of progression at 20 years was $5 \%, 21 \%, 37 \%$, and $58 \%$, respectively (see Table 1 ; [7]).

\section{Work-up}

Due to its high prevalence in the elderly population, screening for MGUS is not recommended [6], even though it has been suggested that $\mathrm{MM}$ is virtually always preceded by MGUS and early detection and subsequent close monitoring may prevent the occurrence of end-organ damage [8]. However, serum electrophoresis and immunofixation are frequently performed in patients presenting with various symptoms ranging from anemia or bone pain to unspecific symptoms like fatigue. Once detected, any paraprotein always warrants thorough work-up. First and foremost, any symptoms or laboratory features suspicious for MM, chronic lymphatic leukemia (CLL), or WM must be investigated. Here it is important to not only evaluate all patients for the presence of the traditional CRAB (elevated calcium level, renal failure, anemia, bone lesions) criteria, but also for the 2014 Slim crite- ria (myeloma defining events, i.e., bone marrow blast cell count of $>60 \%$, ratio of the involved and uninvolved FLC of $\geq 100$, and >one focal lesion in MRI) [1]. Also, it is important to make the correct distinction between MGUS and smoldering myeloma (SMM) as the latter shows a significantly higher rate of progression of about $10 \%$ per year and therefore requires closer monitoring [9]. Laboratory testing should include a complete blood count with differential, blood chemistry, serum and urine electrophoresis with immunofixation, and measurement of FLCs. According to both the European Myeloma Network (EMN) and the International Myeloma Working group (IMWG) guidelines, bone marrow examination can be deferred in patients with low risk disease (i.e. IgG, M-protein of $\leq 15 \mathrm{~g} / \mathrm{L}$, and normal FLC ratio) without symptoms or laboratory anomalies. In all other patients, i.e. IgA or IgM subtypes, an M-protein of $>15 \mathrm{~g} / \mathrm{L}$, or an abnormal FLC ratio, bone marrow biopsy is recommended [6, 9]. If no bone pain is present, bone imaging studies can also be omitted in low risk settings (IgG $>15 \mathrm{~g} / \mathrm{L}$ or IgA $>10 \mathrm{~g} / \mathrm{L}$ ) as the probability of bone lesions has been shown to be very low in patients with an $\mathrm{M}$ spike of less than $15 \mathrm{~g} / \mathrm{L}[6,10]$. Regarding the choice of imaging technique, whole-body low dose computed tomography (CT) is becoming the new standard of care rather than conventional skeletal surveys due to its ability to detect osteolytic lesions at much earlier stages than conventional X-rays, which may result in upstaging and earlier initiation of treatment [11]. Due to its very low rate of progression in patients with light-chain MGUS, the EMN does not recommend bone marrow biopsy or imaging studies except in cases with highly abnormal FLC ratio (i.e., $>10$ or $<0.10$ ) [6].

In patients with impaired renal function, evaluation of any underlying conditions that may be the cause for these changes is paramount. This is particularly important, since MGUS usually affects older patients with numerous comorbidities. If no cause can be determined, referral to a nephrology specialist for further investigation and possible kidney biopsy may be advisable. In MGUS with an abnormal FLC ratio, work-up and monitoring should also include N-terminal pro-B-type natriuretic peptide (NT-pro-BNP) levels, as well as urinary protein either from 24 -h urine collection or protein/creatinine ratio in the spot urine for early detection of organ damage that may herald the onset of amyloid light-chain (AL) amyloidosis [6].

Table 2 Risk-based recommendations for follow-up in monoclonal gammopathy of undetermined significance (MGUS) patients [6]

\begin{tabular}{|c|c|c|c|c|}
\hline Follow-up & Low-risk MGUS & $\begin{array}{l}\text { Non-low-risk } \\
\text { MGUS }\end{array}$ & Light-chain MGUS & MGUS and life expectancy $<5$ years \\
\hline- & $\begin{array}{l}\text { At } 6 \text { months, and if stable, every } 1-2 \text { years or } \\
\text { No further follow-up but additional investigations only in the } \\
\text { case of symptoms suggestive of progression }\end{array}$ & $\begin{array}{l}\text { At } 6 \text { months } \\
\text { and annually } \\
\text { thereafter }\end{array}$ & $\begin{array}{l}\text { At } 6 \text { months } \\
\text { and annually } \\
\text { thereafter }\end{array}$ & $\begin{array}{l}\text { No further follow-up, but additional inves- } \\
\text { tigations only in the case of symptoms } \\
\text { suggestive of progression }\end{array}$ \\
\hline
\end{tabular}




\section{Follow-up}

Due to the steady progression rate, most MGUS patients need lifelong follow-up. The recommendations on follow-up from the various guidelines differ somewhat in certain aspects [12]. The most recent guidelines from the EMN recommend a risk-adapted approach (Table 2) based on the Mayo Clinic risk stratification model $[6,7]$. Patients in the low-risk cohort with a 20 -year risk for progression of $5 \%$ should be followed-up at 6 months and then every 1-2 years if there is no change in the paraprotein levels. In select cases follow-up can be suspended if the disease remains stable for a long time and only picked up in the case of symptoms suggestive for progression. Intermediate and high-risk, as well as light-chain MGUS cases, should be followed-up after 6 months and annually thereafter. In patients with a life expectancy of 5 years or less due to age or other comorbidities, no follow-up is recommended in asymptomatic patients. Appropriate follow-up can be provided in a primary care setting and should include history, physical examination, quantification of the M-protein, complete blood count, creatinine, calcium levels, NT-pro-BNP/ proBNP, and urinary albumin [6].

\section{When to suspect more: determining the undetermined}

There are a number of conditions that are associated with a monoclonal gammopathy and organ damage without fulfilling the criteria for MM. For these increasingly recognized disorders, the term monoclonal gammopathy of clinical significance (MGCS) was recently coined [13]. The common feature of all MGCS is that, while there is only a small plasma cell clone in the bone marrow, the paraprotein causes organ damage through various mechanisms such as deposition in organ tissues, interaction with the complement system, or through direct autoantibody activity of the monoclonal immunoglobulin itself. Kidney dysfunction with proteinuria should trigger evaluation for monoclonal gammopathy of renal significance (MGRS) or kidney AL amyloidosis, while cardiac failure that is rapidly progressing without any prior history of cardiac dysfunction or hypertrophic left ventricular cardiomyopathy can be suggestive for cardiac AL amyloidosis [14]. Early recognition of these disorders can help prevent progression and loss of organ function, which is associated with a very poor outcome. Also, any unexplained symptoms such as bleeding, skin lesions, polyneuropathy, or B-symptoms should trigger intensified evaluation. Conversely, the condition caused by the paraprotein is sometimes known well before the discovery of the paraproteinemia. This is frequently the case in situations where the presenting syndrome did not respond to conventional treatment. Often, treatment of the causative paraproteinemia rapidly improves the condition. The exact prevalence rate of MGCS is unknown, since it remains underdiagnosed as the connection between symptoms and the underlying paraproteinemia are often overlooked.

\section{Conclusion}

MGUS is a common premalignant condition found in over $3 \%$ of people over the age of 50 years that can precede the development of MM, WM, NHL, AL amyloidosis, or MGRS. While progression rates are low, careful and thorough work-up time of diagnosis is necessary to adequately distinguish MGUS from paraprotein-associated diseases. Follow-up should be lifelong and risk-based, focusing on the early detection of end-organ damage.

\section{Take-home messages}

- MGUS is a premalignant condition common in patients over the age of 50 years with a low risk for progression to $\mathrm{MM}$ and associated conditions.

- A thorough risk-adapted approach for initial diagnosis, follow-up, and investigations is recommended.

- Under certain circumstances, a paraprotein may warrant treatment even when criteria for MM are not fulfilled.

Funding Open access funding provided by Medical University of Vienna.

Conflict of interest G. Jeryczynski and M.-T. Krauth declare that they have no competing interests.

Open Access This article is licensed under a Creative Commons Attribution 4.0 International License, which permits use, sharing, adaptation, distribution and reproduction in any medium or format, as long as you give appropriate credit to the original author(s) and the source, provide a link to the Creative Commons licence, and indicate if changes were made. The images or other third party material in this article are included in the article's Creative Commons licence, unless indicated otherwise in a credit line to the material. If material is not included in the article's Creative Commons licence and your intended use is not permitted by statutory regulation or exceeds the permitted use, you will need to obtain permission directly from the copyright holder. To view a copy of this licence, visit http://creativecommons.org/licenses/by/4.0/.

\section{References}

1. Rajkumar SV, Dimopoulos MA, Palumbo A, et al. International myeloma working group updated criteria for the diagnosis of multiple myeloma. Lancet Oncol. 2014;15(12):e538-48.

2. Kyle RA, Therneau TM, Rajkumar SV, et al. Prevalence of monoclonal gammopathy of undetermined significance. NEngl J Med. 2006;354(13):1362-9.

3. Kyle RA, Larson DR, Therneau TM, et al. Long-term follow-up of monoclonal gammopathy of undetermined significance. NEnglJ Med. 2018;378(3):241-9. 
4. Treon SP, Xu L, Yang G, et al. MYD88 L265P somatic mutation in Waldenstrom's macroglobulinemia. N Engl J Med. 2012;367(9):826-33.

5. KingRL, GonsalvesWI,AnsellSM, etal. Lymphoplasmacytic lymphoma with a non-IgM paraprotein shows clinical and pathologic heterogeneity and may harbor MYD88 L265P mutations. Am JClin Pathol. 2016;145(6):843-51.

6. van de Donk NW, Palumbo A, Johnsen HE, et al. The clinical relevance and management of monoclonal gammopathy of undetermined significance and related disorders: recommendations from the European myeloma network. Haematologica. 2014;99(6):984-96.

7. Rajkumar SV, Kyle RA, Therneau TM, et al. Serum free light chain ratio is an independent risk factor for progression in monoclonal gammopathy of undetermined significance. Blood. 2005;106(3):812-7.

8. Goyal G, Rajkumar SV, Lacy MQ, et al. Impact of prior diagnosis ofmonoclonalgammopathyon outcomesinnewlydiagnosed multiple myeloma. Leukemia. 2019;33(5):1273-7.

9. Kyle RA, Durie BG, Rajkumar SV, et al. Monoclonal gammopathy of undetermined significance (MGUS) and smoldering (asymptomatic) multiple myeloma: IMWG consensus perspectives risk factors for progression and guidelines for monitoring and management. Leukemia. 2010;24(6):1121-7.

10. Mangiacavalli S, Cocito F, Pochintesta L, et al. Monoclonal gammopathy of undetermined significance: a new proposal of workup. Eur J Haematol. 2013;91(4):356-60.
11. Simeone FJ, Harvey JP, Yee AJ, et al. Value of lowdose whole-body CT in the management of patients with multiple myeloma and precursor states. Skelet Radiol. 2019;48(5):773-9.

12. Go RS, Rajkumar SV. How I manage monoclonal gammopathy of undetermined significance. Blood. 2018;131(2):16373.

13. Fermand JP, Bridoux F, Dispenzieri A, et al. Monoclonal gammopathy of clinical significance: a novel concept with therapeutic implications. Blood. 2018;132(14):1478-85.

14. Gertz MA. Immunoglobulin light chain amyloidosis: 2020 update on diagnosis, prognosis, and treatment. Am J Hematol. 2020;95(7):848-60. https://doi.org/10.1002/ajh. 25819.

Publisher's Note Springer Nature remains neutral with regard to jurisdictional claims in published maps and institutional affiliations.

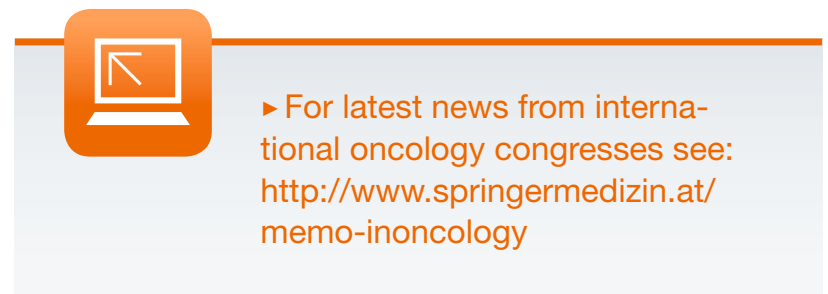

